\title{
An Study on Poverty Alleviation by Tourism in the Border Area Between China and Myanmar
}

\author{
Yaling $\mathrm{Li}^{1}$, Rui Liu${ }^{1}$, Yuting $\mathrm{Li}^{1}$ \\ ${ }^{1}$ School of Business and Tourism Management, Yunnan University, Chenggong District, Kunming, Yunnan, China, 650500
}

\begin{abstract}
At present, China is engaged in the battle of poverty alleviation. The poverty problem in the China-Myanmar border area is an important issue affecting the construction of a moderately prosperous society in China's Yunnan Province and even the whole country. The border area between China and Myanmar is rich in tourism resources and a large number of ethnic minorities live there. The ethnic minority customs are gorgeous. The border area between China and Myanmar has beautiful scenery and rich tropical customs. The tourism poverty alleviation strategy can be implemented and tourism development projects can be established according to local conditions. The development of border tourism between China and Myanmar can not only attract tourists to appreciate the beautiful tropical and subtropical landscapes and feel the simple lifestyle of ethnic minorities, but also promote the development of local economy. The development of border tourism can also strengthen people-to-people exchanges, enhance the communication between the two countries, and help to carry out international trade and seek economic cooperation.
\end{abstract}

\section{Introduction}

With the rapid development of tourism and the improvement of international environment stability, border tourism has been paid more and more attention. The study of border tourism began in the late 1970s. In the early 1990s, with the acceleration of the process of global economic integration, frontier tourism research has also come to a climax. Since the 21 st century, with the rapid development of tourism in Asian countries and the continuous strengthening of international cooperation, the research on border tourism has also increased rapidly. In 2006, Sofield proposed "Border Tourism" to represent border tourism for the first time. International Tourism Organization believes that border tourism should include elements such as "overnight" and certain travel distance. Timothy and others believe that border tourism should also include cross-border one-day Tours. Timothy believes that border tourism activities include shopping, pornography, gambling, fine dining, drinking and so on. Chinese scholars have defined border tourism in a narrow sense and a broad sense. In a narrow sense, border tourism should include two elements: crossing the border, and the scope and time limit of tourism should be decided by the local government. In other words, border tourism is considered as a part of transnational tourism. In the broad sense, border tourism removes the restriction of crossing ports, including domestic border tourism and cross-border border tourism. As can be seen from this, with the development of tourism in border areas, although the concept of border tourism has not reached the same definition. However, most scholars believe that it takes place near the border, and it is a tourism activity that plays a positive role in the prosperity of frontier economy, the consolidation of border stability, the promotion of the country's opening up to the outside world and the international economic and trade cooperation.

China's poverty alleviation and development work began after the founding of the People's Republic of China and has gone through seven stages of development. The main goal of poverty alleviation is to solve the problem of food and clothing for the people. In some areas, the poverty alleviation effect has been obvious and the poverty has been significantly improved, but the poverty in border areas is still serious. As the problem of poverty alleviation becomes more and more urgent, border tourism as a means of poverty alleviation has received more and more attention. The related research contents mainly focus on three aspects: the research on the ideas of poverty alleviation and development of border tourism, the research on the residents' conflicts in the poverty alleviation of border tourism, and the evaluation of the effect of poverty alleviation of border tourism.

Yunnan is located in the southwest of China with a border of 4,060 kilometers, bordering Myanmar, Laos and Vietnam, among which the China-Myanmar border is 1,997 kilometers long. The border area between China and Myanmar has many high mountains and valleys, and the traffic is extremely inconvenient. Besides, it is far 
from the core economic area and the level of economic development is low. The poverty problem in the border area between China and Myanmar is an important factor affecting Yunnan Province and even the whole China to build a well-off society in an all-round way. Fortunately, the border area of China and Myanmar is rich in tourism resources, and there are many ethnic minorities living in the border area. The ethnic minorities have gorgeous customs, and the border area of China and Myanmar has beautiful scenery and rich tropical customs, so the tourism poverty alleviation strategy can be implemented. The National Tourism Administration has issued a circular on further improving the current poverty alleviation work through tourism. At present, the poverty alleviation work mechanism of tourism has been basically established, the policy system has been increasingly improved, the types of products have been enriched, and the social influence has continued to expand. The development of tourism has become a powerful tool and important support for poverty alleviation in many poverty-stricken areas. We will make solid progress in integrating tourism development with poverty alleviation. At present, China has entered the decisive stage of building a well-off society in an allround way, so it is necessary to put the border tourism policy into effect, take practical actions to help the poor people who really need help, provide more development opportunities for the poor people, and improve their ability to get rid of poverty.

\section{Literature review}

In general, after the development in recent years, border tourism has become an important engine for economic and social development in border areas. Scholars are also paying more and more attention to border tourism. The academic research literature on border tourism is also increasing gradually, and the research content mainly focuses on the following aspects:

\subsection{Study on the Comprehensive Effect of Border Tourism}

In terms of ecological effect, Prokkola (2010) and Martine (2012) respectively took the border areas of Finland and Sweden and the border areas of Bengal as cases to study the impact of border tourism on border ecological effect. Milenkoviu (2008) and Plumptre (2011) studied the importance of cross-border tourism for ecological and environmental protection.In terms of social and cultural effects, Jakosuo (2011) and Arrington (2010) studied the impact of tourism policies on border tourism by taking Karelia in the border area of Finland and the border area of Zimbabwe and Zambia as examples respectively. Wang Lili and Ming Qingzhong (2018) analyzed the role changes of ethnic minority women in border tourism from the perspectives of economic role, cultural role, educational role and family power by applying Bourdieu's practical theory. In terms of economic effect, Hampton (2010) took IndonesiaMalaysia-Singapore Growth Triangle (IMS-GT) as a case and found that cross-border tourism in Singapore could bring significant economic benefits to the local reception community, including creating jobs, increasing economic income and driving the development of related industries. Sullivan et al. (2012) used the input-output analysis method to quantitatively study the tourism consumption types at the border between the United States and Mexico, and found that cross-border tourists spent the most on shopping, followed by spending on diet and sightseeing. Li Yuhong and Ma Yong (2008) believe that border tourism is an economic undertaking with considerable benefits and can effectively promote the pace of poverty alleviation and prosperity in border areas.

\subsection{Study on the Development Path of Border tourism}

Gelbman (2008), Li Yanqin, Liu Liping et al. (2016) analyzed the conflict mechanism and solutions of border tourism. Liu Jijie (2015), Lou Yang (2017) et al analyzed and studied the border ports in Northeast China and the China-Vietnam border areas in Yunnan respectively, put forward the tourism spatial layout of "six regions -- five belts" and "one belt, three cores and four poles", and put forward the corresponding development ideas. Xu Ning, Thuden Kezhu, Meng Yuan (2017) et al pointed out that the development modes of border tourism poverty alleviation include ecological culture tourism poverty alleviation mode, folk culture tourism poverty alleviation mode and border trade tourism poverty alleviation and development mode. $\mathrm{Yu}$ Haiyan (2017) discussed the upgrading path of China-Vietnam cross-border tourism cooperation from five aspects:strengthening bilateral cooperation, developing tourism products, building tourism information platform, promoting customs clearance management mode, and carrying out the strategy of "tourism + culture".

\subsection{Study on Tourism Cooperation Mechanism of Border Tourism Region}

Lovelock (2006) established an analysis framework for influencing factors of cross-border cooperation from three levels: macro, meso and micro. Huang Ailian (2011) studied the marketing mechanism of cross-border tourism between China and Vietnam. Zhou Can (2015), Luo Kui and Hu Fusheng (2017) discussed the path of establishing and deepening tourism cooperation.

\subsection{Study on the Competitiveness of Border Tourism}

Horton (2011) analyzed the reasons why medical tourism in Mexico is so competitive. Shi Yuqing (2014), Guo Xiangyang (2017), and Wu Jianli (2017) respectively used AHP, factor analysis and principal component analysis methods to analyze relevant indicators of 136 border counties in China and eight border cities and prefectures in Yunnan, to find out the 
strength of tourism competitiveness of each region, and put forward suggestions to improve tourism competitiveness. Wang Juan, Ming qing-zhong, Lou Siyuan (2018) compared the tourism resources, traffic conditions, economic level and location conditions of Guangxi and Yunnan provinces and pointed out that the border tourism development of the two provinces and regions was objectively competitive to a certain extent. The comparative advantages of the two provinces should be brought into play, and the competition should be turned into cooperation to speed up the development of tourism in the southwest border areas.

\section{Causes of poverty and poor tourism in the border areas between China and Myanmar}

The border between China and Myanmar is 1,997 kilometers long, covering five prefectures, cities and prefectures. Due to historical and geographical factors, the economic development level in this region is backward, and the living standard of farmers is generally low, and the poverty level is quite large. And these areas have a single industrial structure, the primary industry is relatively large. The low level of education of the local population makes it difficult to escape poverty and the rate of return to poverty is high. The causes of poverty are as follows:

\subsection{Harsh Natural Environment}

The remote location of the China-Myanmar border area and poor production and living conditions have hindered the farmers from poverty and prosperity. The earthquake is an important factor affecting the economic development of this area. There are many mountain roads in this area, which are prone to mud-rock flow, landslide and other natural disasters. All these will seriously affect the production and life of local residents and the development of local economy.

\subsection{Drug Abuse and the Spread of AIDS}

The China-Myanmar border is adjacent to the "Golden Triangle". The special location of the border area between China and Myanmar has made it a paradise for drug dealers. As of November 9, 2018, the Frontier Extreme Brigade of Yunnan Province has cracked 1,832 drug cases, with a total amount of drug extreme exceeding 8.8 tons. Affected by the environment, local residents have also developed the habit of feeding and sucking. Take Xishuangbanna Prefecture as an example. Xishuangbanna is adjacent to "Jinshan Jiao". The prefecture has 15 townships bordering the border between Myanmar and Laos. It has a border of 966.3 kilometers with no natural barrier and numerous trails. Due to the familiarity with the terrain, local residents can easily enter Myanmar and obtain drugs easily. In such an environment, the local population can easily become addicted to drugs. The huge costs of drug use impoverish families that are not already wealthy.

\subsection{The Effects of War and Border Conflict}

In 2015, the war broke out in northern Myanmar. During the fighting between the Myanmar government forces and the "civilian armed forces", Myanmar military aircraft crossed the border and artillery shells fell into China for many times, causing deaths and injuries to Chinese border residents and seriously threatening the security and stability of the China-Myanmar border areas as well as the life and property safety of border residents. The legacy of the war has also become a factor affecting the lives of border residents. After the "3.6 war" in 2017, the Myanmar army planted a large number of mines along the China-Myanmar border, especially between border posts 122 and 127. It is common for border people in Kokang to touch landmines by mistake.

\subsection{Industrial Structure is Unreasonable, Income Growth is Weak}

The industrial structure of China-Myanmar border area is relatively simple, and the proportion of agriculture is far higher than the national level. The border areas between China and Myanmar are mostly mountainous areas with uneven terrain, less usable arable land and poor soil quality. Some villages have only $0.1 \mathrm{mu}$ of arable land per capita. Agricultural production costs are high, and there is little surplus after the harvest meets the needs of the family. In addition, agriculture has low added value and is also affected by drought, flood and other natural disasters and market risks. Due to the distance from the market and inconvenient transportation, some crops are faced with the problem of difficult sales after harvest. Farmers in the China-Myanmar border area have two main sources of income, farming and migrant work. On the one hand, agricultural income is low.On the other hand, local residents are generally poorly educated and lack professional skills. As migrant workers, they can only engage in low-skilled jobs with relatively limited salaries.

\subsection{Poor Infrastructure}

The development of tourism industry needs the support of sound infrastructure. In the process of poverty alleviation through tourism, China-Myanmar border areas need to invest a lot of money in infrastructure construction. However, due to the sluggish development of local economy, the government is unable to support the huge cost of infrastructure construction. At present, the infrastructure of the China-Myanmar border area is very backward. The accessibility of the area is severely affected by the lack of transport. Most domestic tourists visiting the China-Myanmar border will change trains at Kunming. Take Kunming to Xishuangbanna as an example. The distance between the two cities is about 500 kilometers, and there is no direct train. It takes eight or nine hours by bus and about one hour by plane. 
Although the China-Myanmar border is rich in tourism resources, the time cost of a visit is high, and many tourists give up the idea of visiting the border. The China-Myanmar border area is not only backward in transportation, but also imperfect in communication, electricity and water conservancy facilities. Many villages also face water difficulties and unstable electricity. Poor infrastructure is still struggling to support the normal lives of local residents, let alone the diverse needs of tourists.

\subsection{Product Homogenization Development}

Although the tourism resources in the border areas of China and Myanmar are very rich, the homogenization of tourism products is also very serious. Take the tourism of ethnic minorities along the border of China and Myanmar as an example. Although there are many ethnic minorities living along the border of China and Myanmar, the costumes, festivals and customs of each ethnic group have their own characteristics. But thanks to the development of transportation and communication, these ethnic groups have also begun to leave their villages and reach out to the outside world. Influenced by trends and other ethnic groups, the cultures of different ethnic groups learn from each other and absorb each other with strong harmonization. The costumes, songs and dances, diet, festivals and other aspects of various ethnic groups have a high degree of similarity. From the perspective of the development of folk tourism resources in various scenic spots, marriage, festivals, food, clothing, singing and dancing are mainly presented on the stage, and the development methods are highly similar. But this kind of extensive development mode, the output added value is low, the economic benefit is small. It is easy to cause cultural distortion and excessive commercialization.

\subsection{Education is Poor and Talent is in Short Supply}

In the China-Myanmar border area, there is a serious lack of investment in teaching. Schools are less distributed and the teaching conditions are poor. Some schools have only one classroom, only the first and second grade, the teaching facilities are backward. Most teachers do not want to teach in these places, resulting in a low number of teachers. The teaching level of teachers is also very different from that of the city. At the same time, parents here do not pay enough attention to education, and many children drop out of primary school. In general, illiteracy rates are generally high here. In some villages, the illiteracy rate exceeds $90 \%$. Villagers lack the basic quality and professional skills needed to participate in tourism development and development. There are few local colleges and universities, and most of the students trained by the few colleges and universities go to cities with developed tourism or economy such as Kunming, while few talents stay in the local area for development. Many of the local college students who go abroad also stay to work in other places.
Few have returned to build their hometowns. But talent is the key to economic development. The service quality of tourism practitioners directly affects the production of tourism products.

\section{An effective way to get rid of poverty and become rich: measures to develop China-Myanmar border tourism}

Nujiang Prefecture, Dehong Prefecture, Lincang Prefecture, Xishuangbanna Prefecture and $\mathrm{Pu}$ 'er City on the border of China and Myanmar have become economically underdeveloped areas in Yunnan due to their special natural environment, geographical location and historical and cultural characteristics. However, there are more than 20 ethnic minorities living along the border between China and Myanmar. Some of them are of the same origin, share the same language and have similar customs. A variety of national festivals such as the water-splashing festival of the Dai nationality, the visual singing festival of the Jingpo nationality and the flower festival of the $\mathrm{Nu}$ nationality have become one of the highlights to attract tourists. The primeval forests of Xishuangbanna, the cliff paintings of Lincang and the $\mathrm{Nu}$ River Gorge, also known as the Oriental Grand Canyon, add endless charm to the border tourism of Yunnan. The China-Myanmar Tourism Cooperation Agreement and the Memorandum of Understanding on Chinese Citizens' Self-financed Tours to Myanmar signed by China and Myanmar in 2000 not only make Myanmar one of the destination countries for Chinese citizens' self-financed Tours, but also lay the foundation for China-Myanmar tourism cooperation. Border trade between China and Myanmar has a long history. With frequent exchanges between the governments of the two sides and the support of projects such as the Western Development Project, the Mekong River Sub-region Economic Development Project and the China-Myanmar Border Economic Cooperation Zone, China-Myanmar border tourism enjoys unique advantages.

In recent years, the tourism development in Yunnan and Myanmar has been accelerating, and with the increase of Chinese government's tourism investment, the tourism infrastructure will continue to improve, and the tourism development potential of both places is huge. At the same time, with the construction of ChinaMyanmar Economic Corridor, tourism can effectively solve the problem of idle labor force in China-Myanmar border areas and promote local economic development and social stability due to its strong driving force. Developing border tourism along the China-Myanmar border is an effective way to get rid of poverty in this region.

\subsection{Developing Innovative Tourism Products}

We can give full play to the advantages of the border areas, such as rich exotic customs, strong ethnic customs and beautiful ecological environment, and explore the 
connotation of tourism resources. On the basis of traditional tourism products, we can develop special tourism products, such as sports adventure Tours, tropical food Tours, festival Tours, health care and pension holidays, in combination with various forms of self-drive Tours, land-to-land self-driving Tours and self-help Tours, to promote the transformation and upgrading of the tourism industry. First, it takes Yunnan's Ruili, Wanting, Luxi, Gengma, Tengchong, Dehong and many other counties and cities as the core, and relies on ethnic cultural resources to create a tourism circle of ethnic customs and culture. Second, with the Theravada Buddhist cultural resources of Dehong and Banna as the core, we can build the Theravada Buddhist holy land tourism circle. Third, we can make full use of hot spring resources in Tengchong, Yunnan, LancangMekong River resources in Banna, tea culture resources, etc., to create a leisure and vacation tourism circle. Finally, three major tourism circles should be adopted to promote the development of tourism in the areas around the China-Myanmar border.

The design of leisure and health tourism products is mainly aimed at people with high work pressure and generally high demand for leisure and health. Therefore, for this group of people, the product should focus on health and leisure, with the main purpose of satisfying tourists' sports and leisure and participating experience, make full use of all kinds of tourism resources in the China-Myanmar border, and actively create a new brand of health and health tourism in leisure, health and fashion. At the same time, relying on Ruili's rich forest resources and rural tourism resources, combining forest exploration, forest hiking, forest tai chi and yoga and other forest health products, as well as cross-border cycling, pastoral experience and other health care rural tourism products, the main development system of leisure health care tourism products has been formed. We can also integrate the rich hot springs, beaches and other tourism resources in Ruili and the border section of Myanmar, and develop tourism products such as hot springs and beach health, so as to meet the needs of tourists for medical treatment. In addition, the construction of rehabilitation and convalescence facilities should be improved and the border tourism city of rehabilitation and convalescence should be actively built.

\subsection{Building a Pilot Area for Cross-Border Tourism Between Yunnan and Myanmar}

In the process of tourism cooperation, Yunnan-Myanmar cross-border tourism cooperation zone can be established by relying on Ruili - Majie - Mandalay section railway. The cooperation zone will be centered on Ruili in Yunnan Province and Mujie and Mandalay in Myanmar. In accordance with the principle of joint development and shared benefits, the three sides should strengthen cooperation in tourism policy, tourism information technology and tourism publicity. At the same time, the tourism resource characteristics of the three regions should be fully integrated, and the cross-border tourism brand of Myanmar should be jointly built to enhance the competitiveness of regional tourism development. Secondly, by taking "Ruili and Mujie" as the core, it can radiate and drive the tourism development of surrounding regions, so as to realize the comprehensive development of China-Myanmar border tourism.

\subsection{Improving Infrastructure}

The poor infrastructure in the China-Myanmar border area is a serious impediment to the development of the local economy. Strengthening infrastructure construction plays an important supporting role in developing the local economy, promoting the increase of farmers' income and improving the backward situation of the local countryside. Therefore, the government should invest more in improving the infrastructure in the area. First of all, we should improve the transportation conditions, solve the problem that local residents have difficulty in traveling, and improve the accessibility of tourists. Secondly, we should ensure the basic electricity consumption in rural areas, make good use of the rural power grid reconstruction policy, and transform and upgrade the distribution network to achieve electricity for every household. At the same time, communication should be strengthened.

\subsection{Strengthening Education and Training of Employees}

The first step is to change people's minds. The border area between China and Myanmar is remote, far from more economically developed towns. In border areas, infrastructure such as transportation and communication is backward and information is relatively blocked, so the impact of modern civilization is small. Most people's living circle is still limited to the surrounding villages, and they retain the traditional sense of smallholders and the sense of getting along, and they have poor ability to accept new things and new information. Generally speaking, the comprehensive quality of the povertystricken population in the China-Myanmar border areas is low and their ideas are outdated. People's ideas are outdated, and their ability and awareness to lift themselves out of poverty are weak.

Therefore, in order to alleviate poverty in the ChinaMyanmar border areas, we should first help local residents establish a correct concept of poverty alleviation and help them realize the importance of education. We can raise the villagers' awareness of the country's poverty alleviation policy through the village radio and street propaganda. Village cadres should take the lead in participating in tourism and publicize the benefits of tourism to farmers through their own changes. For farmers lacking skills and skills, the government should train them in the form of organizing them to study in tourism enterprises, or guiding teachers and research institutes in universities to give guidance in poor areas. At the same time, we should make the poor people realize that knowledge can change their destiny and strengthen the cultivation of the next generation. In 
order to reduce the dropout rate of school-age children and improve the quality of education, the government should increase the investment in education in the ChinaMyanmar border areas, build modern school buildings, add libraries, computers and other teaching facilities, and at the same time improve the treatment of teachers and actively attract excellent teachers to engage in education in border areas.

\subsection{Attracting Tourism Talents}

The shortage of talents in the border area between China and Myanmar is an obstacle to the sound development of local economy. In order to accelerate the development of local economy, it is necessary to establish a set of reasonable personnel training, introduction and management mechanism. Firstly, the training of local residents should be strengthened to meet the requirements of grassroots service personnel in the tourism industry. The managers at the grassroots level should be selected from the grassroots staff as much as possible. Although these talents have limited education, they have accumulated rich experience in tourism management at the grassroots level. On the one hand, this selection method can improve the work enthusiasm of grass-roots staff and improve the service quality. On the other hand, tourism income can be retained in the local economy as much as possible to reduce tourism leakage. At the same time, we should accelerate the training of middle - and high-end tourism management personnel. Middle - and high-end tourism management talents are related to the development of the local tourism industry. We should improve the professional skills of managerial personnel through professional training, carry out school-enterprise cooperation, and organize tourism managers to go to colleges and universities for further study.

\subsection{Fostering a Stable Border Environment}

Stabilizing the border environment and establishing peaceful and friendly good-neighborly relations are the basis of border tourism and trade. China and Myanmar share a border of 2,200 kilometers. Whether the situation in northern Myanmar is stable or not is directly related to the security and development of the China-Myanmar border area, and also creates a good environment for the development of border tourism of the two countries.

\section{References}

1. Timothy D J, Butler R W. Cross-boder shopping: A North American perspective[J]. Annals of Tourism Research,1995,22(1):16-34.

2. Timonthy D J. Tourism and Political Boundaries[M]. New York: the Taylor \& Frsncis Group, 2001:9-11.

3. Prokkola E K. Borders in tourism: The transformation of the Swedish-Finnish border landscape[J]. Current Issues in Tourism,2010,13(3):223-238.
4. Martin E, Vigne L. Successful rhino conservation continues in West Bengal, India[J]. Pachyderm, 2012, 51(51):27-37.

5. Jakosuo K. Russia and the Russian tourist in Finnish tourism strategies: The case of the Karelian region $[\mathrm{J}]$. Procedia-Social and Behavioral Sciences,2011,24:1003-1013.

6. Arrington A L, Seif J, Rivettcarnac K. Competing for tourists at Victoria Falls: a historical consideration of the effects of government involvement[J]. Development Southern Africa, 2010, 27(5):773-787.

7. Hampton M P. Enclaves and ethnic ties: The local impacts of Singaporean cross-border tourism in Malaysia and Indonesia[J]. Singapore Journal of Tropical Geography,2010,31(2):239-253.

8. SullivanP, BonnMA, BhardwajV, etal. Mexican national cross border shopping: Exploration of retail tourism[J]. Journal of Retailing and Consumer Services,2012,19(6):596-604.

9. Gelbman A. Border tourism in Israel: conflict, peace, fear and hope[J]. Tourism Geographies, 2008,10(2):193-213.

10. Schindler S, Curado N, Nikolov S C, et al. From research to implementation: nature conservation in the Eastern Rhodopes mountains (Greece and Bulgaria), European Green Belt.[J]. Journal for Nature Conservation, 2011, 19(4):193-201.

11. O'connorN, BolanP. Creating asustainable brand for Northern Ireland through film-induced tourism[J]. Tourism Culture \& Communication,2008, 8(3):147158.

12. LovelockB, BoydS. Impediments to across-border collaborative model of destination management in the Catlins, New Zealand[J]. Tourism Geographies,2006,8(2): 143-161.

13. HortonS, ColeS. Medical returns: Seeking health care in Mexico [J].Social Science \& Medicine,2011,72(11): 1846-1852.

14. Li Fei. Cross-border tourism cooperation zone: exploring a new model of border tourism development [J]. Tourism Science,2013,27(05):1021.

15. Ge Quansheng, Xi Jianchao, Wang Shoukun. China's Border Tourism: Stages, Pattern, Several Key Strategic Issues and Countermeasures [J].

16. Wang Lili, Ming Qingzhong. The role of minority women in the development of border tourism: A case study of Dai women in Mengjing-lai village of Xishuangban Autonomous Prefecture [J]. Guangxi Ethnic Studies,2018(01):41-49.

17. Li Yanqin, Liu Liping. Conflict evolution and countermeasures of tourism poverty alleviation in ethnic villages: A case study of Sino-Russian border village Shiwei [J]. Journal of Southwest University for Nationalities (Humanities and Social Sciences Edition),2016,37(10):130-134. 
18. Geng Guihong, Zhang Lijun. The development of tourism industry in the border region of southwest China: A case study of Dehong in Yunnan and Chongzuo in Guangxi [J]. Journal of Hubei University for Nationalities (Philosophy and Social Sciences Edition),2017,35(02):96-100.

19. Li Yuhong, Ma Yong. The role of border tourism in poverty alleviation in border areas [J]. Heilongjiang Nationalities Series,2002(02):67-73.

20. Li Yanqin, Liu Liping. Conflict evolution and countermeasures of tourism poverty alleviation in ethnic villages: A case study of Sino-Russian border village Shiwei [J]. Journal of Southwest University for Nationalities (Humanities and Social Sciences Edition),2016,37(10):130-134.

21. Liu Jiajie, Xu Shumei, Wang Minglei, Xiao Lin, Tian Ye. A study on the development of border port tourism in Northeast China [J]. World Geographical Studies,2015,24(04):163-17.

22. Lou Yang, Li Qinglei, Gao Dashuai. Research on the development of China-Vietnam border tourism in Yunnan Province [J]. Resources Development and Market,2017,33(09):1114-1117.

23. Xu Ning, Tu Dengke Zhu, Meng Yuan, Zhuo Gacuo M. Study on the thought and mode of poverty alleviation development of Tibet border tourism under the background of "One Belt And One Road" [J]. Tibetan Studies in China,2017(04):134-138.

24. $\mathrm{Yu}$ Haiyan. Challenges and upgrading paths of China-Vietnam cross-border tourism cooperation [J]. Practice of Foreign Trade and Economic Cooperation,2017(09):80-83.

25. Zhou Can. New ideas for deepening cross-border tourism cooperation [J]. Open Review,2015(04):7477.

26. Luo Kui, Zhang Qiang. Border Tourism Development and Free Tourism Zone Construction in China-Kazakhstan International Cooperation Demonstration Zone of the Silk Road Economic Belt [J]. Arid Land Geography,2016,39(05):959-966.

27. Hu Fusheng. The construction of cross-border tourism cooperation zone under the background of "One Belt And One Road" initiative [J]. Tourism Tribune,2017,32(05):1-3.

28. Shi Yuqing, Zhong Linsheng, Chen Tian. Evaluation of tourism competitiveness in China's land border counties [J]. Resources Science,2014,36(06):1133-1141.

29. Guo Xiangyang, Ming Qingzhong, Mu Xueqing, Lou Siyuan, Wang Juan, Wu Jianli. A study on the difference and integration of tourism competitiveness in border regions of Yunnan Province [J]. World Geographical Studies,2017,26(05):147-156.

30. 30. Wu Jianli, Ming Qingzhong, Cai Hgeng, Guo Xiangyang, Yang Yaping. Research on the spatial pattern of tourism competitiveness of border cities and prefectures in Yunnan based on PCA [J].
Resources Development and Market,2017,33(09):1104-1108.

31. Wang Juan, Ming Qingzhong, Lou Siyuan. Research on the development of border tourism competition and cooperation in southwest border provinces $[\mathrm{J}]$. Academic Exploration,2018(01):57-62.

32. Xu Ning, Tu Dengke Zhu, Meng Yuan, Zhuo Gacuo M. Study on the thought and mode of poverty alleviation development of Tibet border tourism under the background of "One Belt And One Road" [J]. Tibetan Studies in China,2017(04):134-138.

33. Yang Yan. A Study on the Poverty Allowance of Ethnic Minority Tourism in the Context of "One Belt And One Road" [J]. Journal of Minzu University of China (Philosophy and Social Sciences),2018,45(02):65-74.

34. Li Yanqin, Liu Liping. Conflict evolution and countermeasures of tourism poverty alleviation in ethnic villages: A case study of Sino-Russian border village Shiwei [J]. Journal of Southwest University for Nationalities (Humanities and Social Sciences Edition),2016,37(10):130-134.

35. Dang Hongyan, Jin Yuanyuan. Targeted poverty alleviation effect of tourism and its influencing factors: A case study of Zuoquan County, Shanxi Province [J]. Economic Problems,2017(06):108-113. 